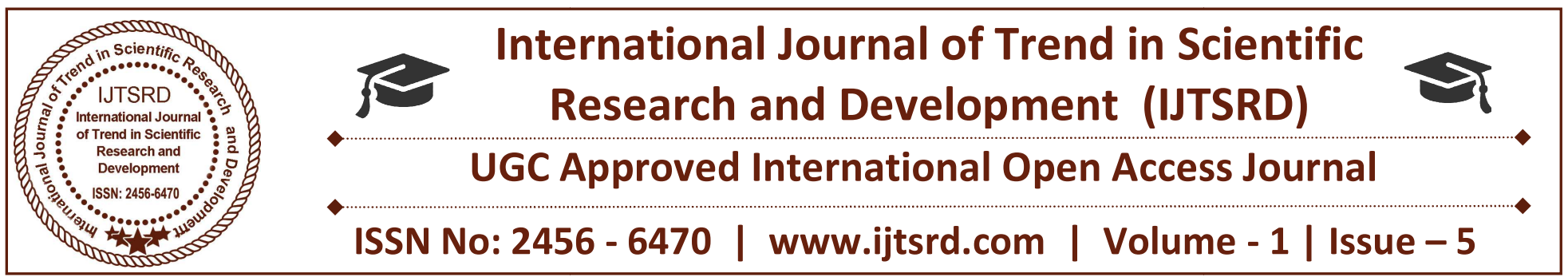

\title{
Comparison of Software Cost Estimation Techniques: An Overview
}

\author{
R. Poorna Chandra Sekhar \\ Research Scholar, Dept. of Computer Sciences, \\ S.V. University College of Commerce Management \\ and Computer Sciences, Tirupathi, A.P
}

\section{ABSTRACT}

The industry of software should be efficient. Due to rapid change in technology, implementation of complex software systems at cheaper cost and the urge to maintain better quality software are some of the major challenges for the software companies. One of the toughest works is cost estimation, in the field of software engineering. It is the estimation of total cost required in developing software. Researchers have proposed various methods of cost estimation. This paper gives an insight into the various models and techniques used in estimating cost of the software. The benefits and drawbacks of the existing cost estimating techniques have been highlighted in this paper. There is as such not any single method which can be regarded as the best method so in this paper it is suggested that a combination of the methods should be used to get an accurate cost estimate.

General Terms: Software Engineering, Software Cost Estimation

Keywords - Software cost estimation, Estimation techniques, Cost models, COCOMO, Algorithmic method, Non-Algorithmic method

\section{INTRODUCTION}

Programming Cost Estimation is procedure of anticipating the exertion required to build up a product framework. The real classifications of model are algorithmic and non-algorithmic having its own particular quality and shortcoming. Determination is a

\author{
Prof Dr. G. Anjan Babu \\ Professor and Head, Dept. of Computer Sciences, \\ S.V. University College of Commerce Management \\ and Computer Sciences, Tirupathi, A.P
}

key component of precision. The evaluations rely on upon exertion, extend term, cost and so forth. Cost

estimation will stay complex issue and explores should enjoy to approach new strategy for this errand. Models in light of Artificial Intelligence methods ought to be utilized for more exact estimation. In this manner programming cost estimation or programming exertion estimation is the way toward anticipating the exertion required to build up a product framework. Programming designing cost models and estimation procedures are utilized for various purposes including; planning, exchange off and chance investigation, extend arranging and specialist, and programming change venture examination. The exactness of the product extend cost estimation has an immediate and huge effect on the nature of the association's product venture choices. Exact cost estimation can lessen the pointless expenses and increment the association's proficiency. Therefore, numerous estimation models have been proposed in the course of the most recent 20 years. Sadly, regardless of the huge collection of involvement with estimation models, the flawlessness of these models is still a long way from being attractive. Programming advancement exertion estimation with the guide of simulated neural systems (ANN) pulled in extensive research intrigue particularly toward the start of the nineties. A key figure choosing a cost estimation display is the precision of its measurements, since these models depend on measurements as their information. The principle commitment of this paper is to give brief writing overview of the utilization of different cost 
estimation strategies, alongside the most recent patterns in the utilization of Artificial Intelligence procedures for Software Development Cost Estimation.

The paper is organized as follows: a review of various techniques for project cost estimation is presented in section 2 and section 3 summarizes existing literature on software project cost estimation. This includes comment on the performance of the estimation models and description of research trends in software cost estimation. The paper closes in Section 4, with conclusion and future research directions.

\section{Algorithmic Methods}

These techniques are intended to give some numerical conditions to perform programming cost estimation. These scientific conditions depend on explore and authentic information and utilize a few contributions for instance Source Lines of Code, number of capacities to perform, and some cost drivers like as dialect, outline technique, ability levels, hazard appraisals, and so on. Algorithmic techniques created many models, for example, COCOMO models, Putnam model, and capacity focuses based models.

2.1.COCOMO Model is one broadly utilized algorithmic cost estimation show is the Constructive Cost Model (COCOMO) which was proposed by Boehm. The fundamental COCOMO show has a straightforward shape:

\section{MAN-MONTHS $=$ K1 $*($ KDLOC $)$ K 2}

Where $\mathrm{K} 1$ and $\mathrm{K} 2$ are two parameters which are reliant on the application and advancement condition. Appraisals from the fundamental COCOMO model can be made more precise by considering different variables concerning the required attributes of the product to be created, the capability and experience of the improvement group, and the product advancement condition. Intricacy of the product has following component:

Unwavering quality data base size required productivity for memory and execution time Capability of examiner and programmer Team involvement in the application area Experience of group in the programming dialect and computer Use of programming designing and tools. This model is a relapse display. It is rely on upon the examination of 63 choose ventures. The essential information is thousand conveyed source guideline.
The issues are:

1. In early period of SDLC, the size is evaluated with extraordinary vulnerability esteem. Along these lines, the precise cost appraise can't be touched base at.

2. The estimation condition is gotten from the investigation of 63 chose ventures. It generally has a few issues outside of its specific condition thus, the recalibration is essential.

The principal rendition of COCOMO show has been encountering expanding challenges in cost assessing of programming created to new life cycle procedures and abilities including quick improvement handle demonstrate, reuse-driven methodologies, protest arranged methodologies and programming process development activity. For taking care of this issue, the most current rendition, COCOMO 2.0, was produced. The real abilities of COCOMO 2.0 are a tailor capable group of programming size models, including object focuses, work focuses and source lines of code; nonlinear models for programming reuse and reengineering. COCOMO demonstrate is likewise filling in as a structure for a broad current information accumulation and investigation push to additionally refine and align the model's cost estimation abilities.

2.2.Putnam Model demonstrates is experimental exertion estimation show. Putnam utilized his profitability levels perceptions to infer the product condition:

\section{Technical consistent $C=$ measure $* B 1 / 3 * \mathbf{T 4} / 3$ Total PM B=1/T4 *(size/C)3}

$\mathrm{T}=$ Required Development Time in years

Size $=$ assessed in LOC

Where: $\mathrm{C}=$ parameter subject to the advancement condition and is resolved on the premise of authentic information of the past undertakings.

Rating for $\mathrm{C}=2,000$ is poor $\mathrm{C}=8000$ is great $\mathrm{C}=12,000$ is phenomenal. This model is exceptionally touchy to the advancement time, diminishing the improvement time can enormously build the individual months required for improvement. One huge issue with this model is that it depends on knowing, or having the capacity to appraise precisely, the span of the product to be created. There is frequently awesome vulnerability 
in the product measure. It might bring about the mistake of estimation.

2.3.Capacity Point Analysis is technique for evaluating the size and multifaceted nature of a product framework as far as the capacities that the frameworks convey to the client. Various exclusive models for cost estimation have adjusted to this sort of approach, as ESTIMACS and $\mathrm{SPQR} / 20$.

This is an estimation which depends on the usefulness of the program. It was first presented by Albrecht. The aggregate number of FP relies on upon the include of particular terms of organization or handling rationale sorts. Following two stages in checking capacity focuses:

1. Including to the client capacities: The crude capacity numbers are touched base at by considering a direct mix of five fundamental programming segments. These parts are

$>$ Outer sources of info,

$>$ Outside yields,

$>$ Outer request,

Rationale inner records and

$>$ Outer interfaces,

Each at one of three unpredictability levels: straightforward, normal or complex. The aggregate of these numbers, weighted by the intricacy level, is the quantity of FC.

2. Adjusting for natural preparing multifaceted nature: The last capacity focuses is touched base at by duplicating capacity number by an alteration calculate that is dictated by considering 14 parts of handling intricacy. This change figure permits the capacity tally to be altered by at most $35 \%$ or $35 \%$.

2.4.Straight Models commonly have the straightforward structure and follow a reasonable condition as underneath:

\section{EFFORT $=\mathbf{a 0}+\sum$ n ai $\mathbf{x i} \mathbf{i}=0$}

Where, a1, a2, are chosen by the data of venture, just permitted esteems for xi are $-1,0,+1$.
2.5.Soothsayer Sem Model parameters are business and business extends normally utilize diviner sem as their fundamental cost estimation strategy. Size of the product is the most critical component in soothsayer Sem technique and a parameter in particular Se is characterized as successful size is processed by deciding the five pointers:

$>$ New Size

$>$ Existing Size

$>$ Reimp

Upgrade and

$>$ Retest

$\mathrm{Se}=$ new size + existing Size $(0.4$ redesign +0.25 reimp +0.35 retest)

After computing the Se the estimated effort is calculated as below:

\section{EFFORT $=$ td $=$ D $-0.2 \times($ Se $/$ Cite $) 0.4$}

Where $\mathrm{D}=$ relevant to the staffing aspects It is determined based on the complexity degree in staffs structure. Cite is computed according to productivity and efficiency of the project method. It is used widely in commercial projects.

\section{Non Algorithmic Methods}

Non Algorithmic techniques utilize some data about the past activities which are like the under gauge extend is required and generally taken a toll estimation handle in these strategies is finished by the investigation of the past datasets.

3.1.Master Judgment Method Expert judgment procedures include counseling with cost estimation master or a gathering of the estimation specialists to utilize their experience and comprehension of the proposed venture to touch base at a gauge of its cost. It is the most usable strategies for the cost estimation. Generally organizations utilized master judgment technique for creating the cost of the item. This strategy utilizing following assessing steps:

Venture pioneer gives every master a detail and an estimation frame.

The specialists round out structures secretly. 
$>$ Venture pioneer assembles a gathering conference in which the specialists examine cost estimation issues with the venture pioneer and each other.

$>$ Venture pioneer gets ready and disseminates a rundown of the cost estimation on an emphasis shape.

$>$ Again specialists round out structures, namelessly.

Steps $d$ and step e are iterated for the same number of rounds as suitable.

3.2.Assessing by Analogy Cost evaluating by relationship implies contrasting the proposed extend with beforehand finished comparable venture where the venture advancement data is known. Real information from the finished activities are extrapolated to cost assess the proposed extend. Relationship technique can be utilized either at framework level or at the segment level. This strategy utilizing following assessing steps:

$>$ Discover the essential attributes of the proposed extend.

$>$ Pick the most comparable finished undertakings whose qualities have been put away in the chronicled information base.

$>$ Discover the gauge for the proposed extend from the most comparable finished venture by similarity.

3.3. Parkinson's Law "Work extends to fill the accessible volume", the cost is controlled by the accessible assets instead of in light of a goal appraisal., If the product must be conveyed in 20 months and 4 individuals are accessible, the exertion is assessed to be $80 \mathrm{PM}$. Despite the fact that it once in a while gives great estimation, this technique is not suggested as it might give exceptionally unreasonable assessments. It does not advance great programming building practice.

3.4. Cost to-win the cost is assessed to be the best cost to win the venture. The cost estimation depends on the client's financial plan rather than the product usefulness. For instance, if a sensible estimation for a venture costs $100 \mathrm{PM}$ yet the client can just exertion 60 PM. It is normal that the estimator is made a request to adjust the estimation to fit $60 \mathrm{PM}$ exertion keeping in mind the end goal to win the venture. This is again not a decent practice since it is probably going to cause an awful deferral of conveyance or drive the estimation group to work extra minutes.

3.5. Best down Estimating Method Top-down assessing strategy is known as Macro Model. Utilizing this assessing strategy, general cost estimation for the venture is gotten from the worldwide properties of the product venture, and after that the venture is divided into different low level instrument or segments. The technique utilizing this approach is Putnam display. Best Down strategy is more pertinent to early cost estimation when just worldwide properties are known. In the early period of the product cost estimation, beat down is extremely valuable on the grounds that there is no point by point data accessible.

3.6. Base up Estimating Method Using base up cost assessing technique, the cost of every product segment is evaluated and after that joins the outcomes to touch base at an expected cost of general venture. Base up technique goes for developing the gauge of a framework from the learning amassed about the little programming segments and their associations. The strategy utilizing this approach is COCOMO's point by point show.

\section{Challenges of Software Cost Estimation}

Programming cost estimation handle confront numerous challenges to get a legitimate and exact gauge for some reasons, since programming is something impalpable, as opposed to the estimation procedure in nature is difficult particularly with immaterial items, managing programming estimation is totally unique in relation to any another estimation procedure in any fields. One of the fundamental troubles in the product cost estimation prepare is the accessibility of information which is expected to check the accuracy of any recommended models, measurements and practical measuring methods, numerous of the models and measuring methods proposed in light of a little measure of information, a few models for instance figure the size and gauges the cost in view of 30 UML documents, so they came about model for this situation doesn't has a high unwavering quality and can't be summed up so it can't be connected in any advancement condition, even the information is extremely touchy since one measuring procedures may deliver a decent gauge in $\mathrm{X}$ programming improvement organization which dwell 
in $\mathrm{X}$ nation yet can't increase same accuracy rate in $\mathrm{Y}$ programming advancement organization in $\mathrm{Y}$ nation, this issue highlighted by Wieczorek and Ruhe, the other face of this point is the deficiency of information right on time in the product procedure and this can be understood by gathering information from various number of tasks and sum one up control for the estimation reason. A standout amongst the most useful Benchmarking dataset is the ISBSG which gave mechanical expansive measure of information about a finished programming ventures, the accessible information is totally identified with tailor-made programming.

The "New and Enhancement Projects" Release 10 contains information of more than 4,000 activities from various nations specified by Dekkers There is an issue in the estimation procedure in holding the best possible and reasonable informational index to approve any sort of measurements, estimating methods or any cost models, this create a genuine issue in enhancing programming estimation prepare, there is ISBSG benchmark informational collection, obviously it enhance the estimation procedure in many fields, yet at the same time insufficient, estimation region require a great deal of nifty gritty information. Another challenges in the estimation procedure is the unsteadiness condition in the innovation world, basically "What is right today may not tomorrow!" this elucidate the fast enhancements and changes in the advancement procedure where a large portion of the models should be aligned and adjusted every now and then to be steady and pertinent under the spot of the present improvement lights, and this require a few factors figures any recommended show.

Moreover, the nature of the product advancement handle where not all the necessity is known, notwithstanding prerequisite crawl issue, additionally the interconnection between the cost components and how each element may influence the last aftereffect of estimation and may impact on some different variables, the product improvement field is exceptionally entangled territory, starting at 2007 the product business use around 600 diverse programming dialects, making around 120 various types of various applications, programming industry representative around 90 masters, numerous sort of many-sided quality, perform 23 distinctive support exercises, 18 distinctive testing exercises, utilize 43 distinctive outline techniques and utilize 38 diverse size measurements These numbers demonstrate the confounded condition of programming improvement and the interconnectivity between its components and demonstrate that the estimation procedure stills a hot region for the scientists to create more strong precise models. Another issue is the affectability of the information utilized as a part of confirming any estimating strategies, measurements or models. Demonstrate that the impacts of information utilized either its organization particular nearby information or organization outside worldwide information demonstrating the distinctions in the outcomes which originating from the information utilized as a part of the estimation procedure, so when the Specialists figure any assessing strategies they should tend to the kind of information used to plan the model or system. Programming cost estimation has another issue in its method where its need a master specialists to make the estimation procedure keeping in mind the end goal to accomplish exact expected gauge, now and again checking the quantity of capacity focuses itself may cost more than the real advancement Another test in programming cost estimation is that There is no particular principles and standard control the entire procedure of programming advancement and particularly in the cost estimation prepare; it still a specially appointed process doesn't obeyed or limited to a specific standard or tenets, so there is a need of some affirmed guidelines and models to control the estimation procedure by any stretch of the imagination.

\section{Selection of Estimation Techniques}

It is very evident from the previously mentioned correlation of the methods that all things considered there is no single system which can be credited as the best one. The benefits and faults of every strategy of estimation are connected, so an amalgamation of these procedures can help in decision out shortcomings of a specific technique. It can lessen the negative impacts of a strategy and can help in growth of their individual quality. Additionally we can cross check one strategy with another. Typically it is prescribed to utilize non algorithmic techniques like estimation by relationship or master judgment strategy for the tasks which are known. Then again for bigger and less known undertakings it demonstrates better to utilize algorithmic techniques. Among the algorithmic models, COCOMO II is greatly improved than COCOMO I as it is not just restricted to utilize Source lines of code yet can make utilization of capacity point, protest point as programming measurements to quantify the span of the product ventures. So 

endeavors ought to be made to utilize mix of the methods to touch base at a superior gauge of the product.

\subsection{Comparison of various cost estimation techniques}

\begin{tabular}{|c|c|c|c|c|}
\hline S. No & Method & Type & Strengths & Weakness \\
\hline 1. & COCOMO & Algorithmic & $\begin{array}{l}\text { Clear results, it's very } \\
\text { common }\end{array}$ & $\begin{array}{l}\text { A lot of data is required, it } \\
\text { is not suitable for any } \\
\text { project }\end{array}$ \\
\hline 2. & Function Point & Algorithmic & $\begin{array}{l}\text { Language free, it's } \\
\text { results are better than } \\
\text { source line of code }\end{array}$ & $\begin{array}{l}\text { Mechanization is hard to } \\
\text { do, it is not considered for } \\
\text { quality output }\end{array}$ \\
\hline 3. & Putnam Model & Algorithmic & $\begin{array}{l}\text { A Probabilistic model } \\
\text { used in a very large } \\
\text { projects }\end{array}$ & Only use large projects \\
\hline 4. & $\begin{array}{l}\text { Seer-Sem } \\
\text { Model }\end{array}$ & Algorithmic & $\begin{array}{l}\text { Used in a very large } \\
\text { projects }\end{array}$ & $\begin{array}{l}\text { It's required } 50 \text { input } \\
\text { parameters which are } \\
\text { increases the complexity } \\
\text { and uncertainty }\end{array}$ \\
\hline 5. & Linear Model & Algorithmic & $\begin{array}{l}\text { It's a best method of } \\
\text { prediction using } \\
\text { linear regression } \\
\text { technique }\end{array}$ & $\begin{array}{l}\text { Little difference between } \\
\text { actual and predicted results } \\
\text { and error is also needed to } \\
\text { calculate }\end{array}$ \\
\hline 6. & $\begin{array}{l}\text { Expert } \\
\text { Judgment }\end{array}$ & $\begin{array}{l}\text { Non- } \\
\text { Algorithmic }\end{array}$ & $\begin{array}{l}\text { Fast prediction, adapt } \\
\text { for a special projects }\end{array}$ & $\begin{array}{l}\text { Success depends on expert, } \\
\text { usually done incomplete }\end{array}$ \\
\hline 7. & Analogy & $\begin{array}{l}\text { Non- } \\
\text { Algorithmic }\end{array}$ & $\begin{array}{l}\text { Works based on } \\
\text { actual experience and } \\
\text { special expert is not } \\
\text { important }\end{array}$ & $\begin{array}{l}\text { Much information is } \\
\text { required about past } \\
\text { projects, in some situations } \\
\text { there are no similar } \\
\text { projects }\end{array}$ \\
\hline 8. & Parkinson & $\begin{array}{l}\text { Non- } \\
\text { Algorithmic }\end{array}$ & $\begin{array}{l}\text { Correlates with some } \\
\text { experience }\end{array}$ & Reinforces poor practice \\
\hline 9. & Price to win & $\begin{array}{l}\text { Non- } \\
\text { Algorithmic }\end{array}$ & $\begin{array}{l}\text { It's often gets the } \\
\text { contract }\end{array}$ & $\begin{array}{l}\text { Generally produces large } \\
\text { over runs }\end{array}$ \\
\hline 10. & Top - Down & $\begin{array}{l}\text { Non- } \\
\text { Algorithmic }\end{array}$ & $\begin{array}{l}\text { Require minimal } \\
\text { project details, } \\
\text { usually faster and } \\
\text { easier to implement } \\
\text { and system level } \\
\text { focus }\end{array}$ & $\begin{array}{l}\text { Less detailed basis and less } \\
\text { stable }\end{array}$ \\
\hline 11. & Bottom - down & $\begin{array}{l}\text { Non- } \\
\text { Algorithmic }\end{array}$ & $\begin{array}{l}\text { More detailed basis, } \\
\text { more stable and } \\
\text { encourage individual } \\
\text { commitment }\end{array}$ & $\begin{array}{l}\text { May overlook system level } \\
\text { costs, requires more effort, } \\
\text { a lot of time consuming }\end{array}$ \\
\hline
\end{tabular}

Table 1: Comparison of Various Estimation Methods

Anticipating real cost assess required to create specific programming is a dull errand. Arranging and planning of programming venture is to a great extent influenced by cost estimation, in this manner it is a fundamental procedure in programming estimation. Cost estimation if done before the start of a venture 
can help in deciding the elements which can be incorporated inside the constrained assets of the venture. It additionally helps in decreasing dangers. So we can state that general cost estimation is exceptionally impactful for the life and calendar of a product extend. Our point ought to be to create such programming which are both shoddy and offer a decent quality. There are numerous strategies for evaluating cost yet as obviously we can't view any single method as the best one as each of the procedures have their own particular points of interest and drawbacks. Endeavors ought to be made to utilize a blend of the estimation strategies to touch base at a superior cost and quality gauge. To deliver dependable assessments it is needed legitimate learning and comprehension of every procedure and the connection between the product properties of each.

\section{REFERENCES}

1) Pressman, Roger S."Software Engineering: A Practitioner's Approach, 6th Edition, McGrawHill, New York, USA, ISBN: 13:9780073019338, 2005.

2) Khatibi Bardsiri,V.,D.N.A.Jawawi,S.Z.M Hashim, and E.Khatibi,'Increasing the accuracy of software development effort estimation using projects clustering",IET Software,2012.

3) "COCOMO II Model definition manual", version 1.4, University of Southern California.

4) Karen T. Lum, Daniel R. Baker, and Jairus M. Hihn "The Effects of Data Mining Techniques on Software Cost Estimation" 2009 IEEE.

5) A. J. Albrecht, and J. E. Gaffney, "Software function, source lines of codes, and development effort prediction: a software science validation," IEEE Trans Software Eng. Vol.SE-9, pp.639-648, 1983

6) B. Boehm, and C. Abts, "Software Development Cost Estimation Approaches - A Survey1", University of Southern California.

7) Attarzadeh, I. Siew Hock Ow, "Proposing a New Software Cost Estimation Model Based on Artificial Neural Networks",IEEE International Conference on Computer Engineering and Technology (ICCET), Volume: 3, Page(s): V3487 - V3-491 2010.
8) Attarzadeh, I. Siew Hock Ow,'Improving the accuracy of software cost estimation model based on a new fuzzy logic model", World Applied science journal 8(2):117-184,2010-10-2.

9) M. Boraso, C. Montangero, and H. Sedehi, "Software cost estimation: An experimental study of model performances", tech. rep., 1996.

10) O. Benediktsson, D. Dalcher, K. Reed and M. Woodman, "COCOMO based effort estimation for iterative and incremental software development", Software Quality Journal, vol. 11, pp. 265-281, 2003.

11) N. Veeranjaneyulu, S.Suresh, Sk.Salamuddin3 and Hye-jin Kim, (2014)," Software Cost Estimation on e-Learning Technique using A Classical Fuzzy Approach", International Journal of Software Engineering and Its Applications Vol. 8, No. 11 (2014), pp. 217-222.

12) Stein Grimstad, et. al, (2006), “A Framework for the Analysis of Software Cost Estimation Accuracy", ISESE'06, ACM 1-59593-2186/06/0009.

13) A.J. Albrecht and J.E. Gaffney, "Software function, source lines of code, and development effort prediction: a software science validation" IEEE Transactions on Software Engineering, , pp. 639-647, 1983.

14) Attarzadeh,I. Siew Hock Ow, "Proposing a New Software Cost Estimation Model Based on Artificial Neural Networks",IEEE International Conference on Computer Engineering and Technology (ICCET), Volume: 3, Page(s): V3487 - V3-4912010. 